\title{
Ammonium Secretion by Colletotrichum coccodes Activates Host NADPH Oxidase Activity Enhancing Host Cell Death and Fungal Virulence in Tomato Fruits
}

\author{
Noam Alkan, ${ }^{1}$ Olga Davydov, ${ }^{2}$ Moshe Sagi, ${ }^{3}$ Robert Fluhr, ${ }^{2}$ and Dov Prusky ${ }^{1}$ \\ ${ }^{1}$ Department of Postharvest Science of Fresh Produce, Agricultural Research Organization, the Volcani Center, \\ Bet Dagan 50250, Israel; ${ }^{2}$ Department of Plant Sciences, Weizmann Institute of Science, Rehovot, Israel; ${ }^{3}$ Department \\ of Dryland Biotechnologies, Jacob Blaustein Institutes for Desert Research, Ben-Gurion University, Sede Boqer Campus, \\ Midreshet Ben-Gurion 84990, Israel
}

Submitted 11 March 2009. Accepted 7 July 2009.

\begin{abstract}
Colletotrichum pathogens of fruit and leaves are known ammonium secretors. Here, we show that Colletotrichum coccodes virulence, as measured by tomato (Solanum lycopersicum cv. Motelle) fruit tissue necrosis, correlates with the amount of ammonium secreted. Ammonium application to fruit tissue induced hydrogen peroxide $\left(\mathrm{H}_{2} \mathrm{O}_{2}\right)$ accumulation. To examine whether the tomato NADPH oxidase, SIRBOH, is a source for the ammonium-induced $\mathrm{H}_{2} \mathrm{O}_{2}$, wild-type and antisense lines abrogated for SIRBOH (SIRBOH-AS) were examined. Wild-type lines produced 7.5-fold more reactive oxygen species when exposed to exogenous ammonium than did SIRBOH-AS lines. $C$. coccodes colonization of wild-type tomato lines resulted in higher $\mathrm{H}_{2} \mathrm{O}_{2}$ production and faster fungal growth rate compared with colonization in the SIRBOH-AS mutant, although the amount of ammonium secreted by the fungi was similar in both cases. Enhanced ion leakage and cell death of fruit tissue were correlated with $\mathrm{H}_{2} \mathrm{O}_{2}$ accumulation, and treatment with the reactive oxygen scavenger $\mathrm{N}$-acetyl-L-cysteine decreased $\mathrm{H}_{2} \mathrm{O}_{2}$ production, ion leakage, and cell death. Importantly, the activation of reactive oxygen species production by ammonium was positively affected by an extracellular $\mathrm{pH}$ increase from 4 to 9 , implying that ammonium exerts its control via membrane penetration. Our results show that $C$. coccodes activates host reactive oxygen species and $\mathrm{H}_{2} \mathrm{O}_{2}$ production through ammonium secretion. The resultant enhancement in host tissue decay is an important step in the activation of the necrotrophic process needed for colonization.
\end{abstract}

Colletotrichum coccodes is a hemibiotrophic pathogen that colonizes unripe, living-host fruit tissue symptomlessly for long periods of time (quiescent biotrophic stage) and activates its colonization during fruit ripening and senescence (active necrotrophic stage) (Prusky 1996; Latunde-Dada 2001). Ammonium accumulation has been detected in many Colletotrichum spp., including C. gloeosporioides, C. acutatum, and C. coccodes (Prusky et al. 2001). The ammonium secreted by Colletotrichum spp. enhances alkalization of the host tissue.

Corresponding author: Dov Prusky; Telephone 972-3-9693880; Fax: 9723-9683622; E-mail: dovprusk@agri.gov.il

*The $\boldsymbol{e}$-Xtra logo stands for "electronic extra" and indicates that Figure 2 appears in color online.
The increase in $\mathrm{pH}$ is an important signal for the induction of fungal gene expression, including the secretion of virulence factors such as pectate lyase (Yakoby et al. 2000; Prusky et al. 2001). The level of ammonium in the infection court is high and can reach approximately $3.5 \mathrm{mM}$, as has been found in avocado and tomato fruits (Prusky et al. 2001; Alkan et al. 2008). Ammonium production by these fungi appears to begin with the activation of fungal proteases and concomitant deamination of the resultant amino acids (Prusky and Yakoby 2003). Pathogenicity of Colletotrichum spp. in different hosts is thought to be related to ammonium accumulation (Prusky et al. 2001; Alkan et al. 2008). Interestingly, the initial acidic pH of the fruit has been shown to be conducive to the enhanced ammonium secretion and host-tissue alkalization that facilitate fungal virulence. The isolation of $C$. coccodes mutants with reduced ammonium production has provided direct evidence for the necessity of ammonium accumulation during Colletotrichum pathogenicity (Alkan et al. 2008), indicating that ammonium accumulation is a critical factor contributing to Colletotrichum spp. necrotrophic development in ripening fruit (Prusky and Yakoby 2003).

Nevertheless, how ammonium contributes to pathogenicity remains an open question. Ammonium may have pleiotropic toxic effects on the host, such as activating the transport of various solutes, changing the concentration of cytosolic protons, or initiating transduction signals that may result in metabolic activation of different plant processes (Mathieu et al. 1994). Direct toxicity symptoms may include effects on the biochemical $\mathrm{pH}$-stat mechanisms in cells, causing differences in the internal $\mathrm{H}^{+}$balance and in membrane flux processes (Britto and Kronzucker 2002). Elucidating the nature of the toxicity involved in fungus-fruit interactions is fundamental to understanding Colletotrichum biology. The lifestyle of pathogenic fungi can be broadly divided into necrotrophs, hemibiotrophs, and biotrophs, depending upon the type of interaction between the fungus and host tissue. Much knowledge about plant-pathogen interactions has been garnered from studies on leaf pathogens. The production of reactive oxygen species (ROS), which precedes a hypersensitive response (HR), has been shown to be associated with increased resistance to biotrophs but can also increase susceptibility to necrotrophs (Greenberg 1997; Gilchrist 1998; Glazebrook 2005; Kliebenstein and Rowe 2008; Shetty et al. 2008). A key element responsible for controlled ROS production in innate immune processes is the evolutionarily highly conserved NADPH oxidases, called respiratory burst oxidase homologs 
$(\mathrm{RBOH})$ in plants, which produce superoxides that are subsequently converted into hydrogen peroxide $\left(\mathrm{H}_{2} \mathrm{O}_{2}\right)$ (Sagi and Fluhr 2006). Arabidopsis AtRBOHD and AtRBOHF mutants show differential effects on disease (Torres et al. 2002) whereas tomato lines with reduced $\mathrm{RBOH}$ levels show reduced wound responses (Sagi et al. 2004).

It has been suggested that the leaf HR is triggered by a signal generated by the balance between nitric oxide and superoxide production (Delledonne et al. 1998). Diverting this signal via superoxide induction and, thus, the subsequent tissue HR has been shown to be important in facilitating infection by the necrotroph Botrytis cinerea, although how the ROS were induced is not known (Govrin and Levine 2000). Tissue colonization by $B$. fuckeliana was also reported to be facilitated by ROS production, in this case brought about by changes in the host's (tomato) antioxidant capacity (Kuzniak and Sklodowska 2005). Thus, a well-established cell stress response in many organisms is ROS accumulation followed by localized cell death (D'Autreaux and Toledano 2007).

Successful colonization of necrotrophic pathogens in fruit has not been followed in the context of pathogenicity facilitation by ROS. The synchronic infection court system developed for studying $C$. coccodes mutants represents a good system for such an analysis (Alkan et al. 2008). We examined whether ROS play a role in contributing to fruit tissue decay as they does by enhancing leaf HR and hypothesized that ammonium could trigger this process. Using tomato (Solanum lycopersicum cv. Motelle) lines with downregulated expression of the tomato NADPH oxidase gene, SIRBOH-antisense (SIRBOHAS), we demonstrate a role for ammonium secretion in the induction of host ROS accumulation. We show that ROS are a key factor in promoting cell death in tomato fruit at the leading edge of the colonizing hyphae. Thus, $C$. coccodes fungi activate a host-based innate immunity-signaling system to enhance their own colonization.

\section{RESULTS}

\section{Ammonium accumulation affects}

\section{C. coccodes pathogenicity and host $\mathrm{RBOH}$.}

A striking feature of $C$. coccodes's lifestyle is the secretion of ammonium. To examine the relationship between ammonium accumulation and fungal colonization of tomato fruit, we compiled the results of seven experiments (41 data points) covering a wide variety of experimental conditions with wildtype and ammonia secretion mutants of $C$. coccodes (Alkan et al. 2008) and under different $\mathrm{pH}$ conditions in the infection court (Fig. 1). A 1-cm epidermal region was excised from the fruit and inoculated with $C$. coccodes and the growth in decay diameter was examined after $48 \mathrm{~h}$. Concentrations of ammonium were found to range from 0.5 to $5 \mathrm{mM}$ and the decay diameter from 0.1 to $2 \mathrm{~cm}$ beyond the initial inoculation-site diameter. Decay development increased in direct relation to the amount of ammonium accumulation $\left(R^{2}=0.865 ; P<0.01\right)$.

These results implied that ammonium is correlated with the success of fungal colonization. To examine for a possible causal relationship between ammonium accumulation by Colletotrichum spp. and tomato fruit tissue necrosis, we analyzed the effect of ammonium on the production of ROS in fruit from wild-type and SIRBOH-AS tomato lines. Wild-type tomato fruit slices treated with 5 and $20 \mathrm{mM} \mathrm{NH}_{4} \mathrm{Cl}$ at $\mathrm{pH} 7.0$ showed a 2.9and 7.5-fold increase in ROS production within 15 min of treatment, as detected by staining with the fluorescent probe $2^{\prime}, 7^{\prime}$ dichlorodihydrofluorescein diacetate (DCF) (Fig. 2A and D) and confocal microscopy (Fig. 2E). Similar treatment of fruit tissue from two independent SIRBOH-AS lines (lines 9 and 12) showed only minor changes in ROS production compared with the untreated control (Fig. 2B and C). The applied ammonium rapidly dissipated over the course of the experiment to $5 \%$ of its initial level (data not shown). Hence, the levels of ammonium used here were physiologically relevant to the infection court as measured in Figure 1. At the lower and higher ammonium concentrations (1 and $50 \mathrm{mM}$ ), a 1.6- and 9.4-fold increase in ROS, respectively, was obtained $15 \mathrm{~min}$ after treatment of the wildtype tomato pericarp (results not shown). The induction was not a result of osmotic changes, because the phosphate-buffered saline (PBS) itself contains $140 \mathrm{mM} \mathrm{NaCl}$. These results showed that SIRBOH-dependent ROS accumulation in tomato fruit tissue is induced by physiologically relevant levels of ammonium. Moreover, confocal microscope pictures taken $30 \mathrm{~min}$ after ammonia application showed ROS accumulation in the cells (Fig. 2E).

Effect of ammonium on membrane stability and cell death.

Our results indicated that fungal necrotrophic development can be enhanced by local cell death induced by ROS production. To monitor early insidious aspects of cell death, cellular ion leakage was determined as a measure of membrane stability in ammonium-treated wild-type and SIRBOH-AS tomato fruit. Ion leakage from the tissue membrane was detected by conductivity measurements and monitored simultaneously with $\mathrm{H}_{2} \mathrm{O}_{2}$ production in treated fruit disks transferred to water. Pretreatment of tomato disks with $20 \mathrm{mM} \mathrm{NH}_{4} \mathrm{Cl}$ increased ROS production and membrane leakage by 1.8- and 4.3-fold, respectively, in wildtype fruit (Fig. 3) compared with only 1.14- and 1.4-fold increases in SIRBOH-AS (line 9). Surprisingly, pretreatment of tomato fruit by direct application of $\mathrm{H}_{2} \mathrm{O}_{2}$ enhanced ROS and membrane leakage by 2.5 - and 3.1-fold, respectively, compared with only 1.4- and 1.3-fold in the SIRBOH-AS lines (Fig. 3).

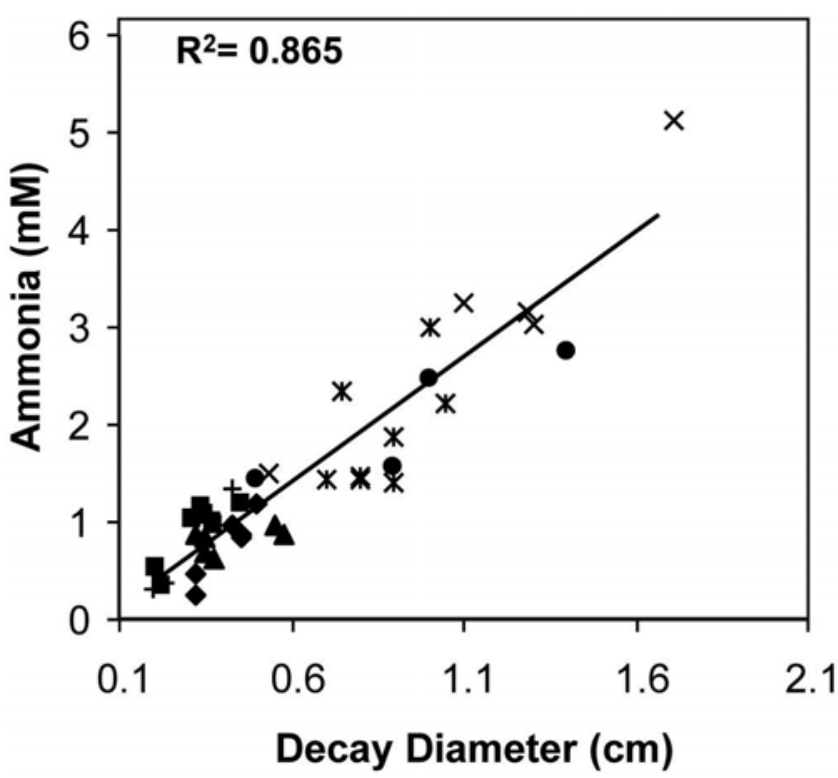

Fig. 1. Accumulation of ammonium in the infection court by Colletotrichum coccodes and decay diameter. Ammonium concentration and extent of the decay diameter beyond the initial hyphal mat inoculation were measured for 41 infection points in seven independent experiments according to the method of Alkan and associates (2008). Symbols: *, are $A^{-}$mutant strains with reduced ammonia secretion inoculated on ripe fruit; $\bigcirc$, are $A^{-}$mutant strains with reduced ammonia secretion inoculated on breaker stage fruit; $\mathbf{\square}$, nit $1^{-}$and nit $3^{-}$mutants inoculated on ripe fruit; + , wild-type (WT) strain inoculated on fruit at various maturation stages (red, color break, and green); $\diamond$, nit $1^{-}$and nit $3^{-}$mutants inoculated on breaker stage fruit treated with ammonia; $\times$, WT strain on ripe fruit treated with phthalate buffer $\mathrm{pH} 4.0$ and $7.0 ; \boldsymbol{\Delta}$, WT strain on breaker stage fruit treated with phthalate buffer $\mathrm{pH} 4.0,4.5,5.0,6.0,6.5$, and 7.0. 
This indicated that $\mathrm{H}_{2} \mathrm{O}_{2}$ can act as a trigger of $\mathrm{RBOH}$. When tomato disks of the wild-type fruit were treated with the ROS scavenger $\mathrm{N}$-acetyl-L-cysteine (NAC) prior to treatment with either ammonium or $\mathrm{H}_{2} \mathrm{O}_{2}$, the increase in ROS was reduced by 63 to $91 \%$ and that of conductivity by 60 to $71 \%$. Only minor effects of NAC were detected in the SIRBOH-AS fruit. NAC also inhibited the increases in ROS and conductivity caused by the water treatments (Fig. 3).

The increased conductivity after $\mathrm{NH}_{4} \mathrm{Cl}$ treatment was reflected in the ensuing cell death, as measured by Evans blue staining. Cell death increased 5- and 14.4-fold in the wild-type fruit 24 and $48 \mathrm{~h}$ posttreatment, respectively, whereas no increase was detected during the same period in SIRBOH-AS line 9 (Fig. 4A and 4B). The increase in cell death in the wildtype fruit after $\mathrm{NH}_{4} \mathrm{Cl}$ treatment was abrogated by pretreatment with the ROS scavenger NAC (Fig. 4D). Because an initial addition of $50 \mathrm{mM} \mathrm{NH}_{4} \mathrm{Cl}$ may be perceived as high, another set of fruit was treated with $5 \mathrm{mM} \mathrm{NH} \mathrm{NH}_{4} \mathrm{Cl}$ reapplied every $6 \mathrm{~h}$ for 24 and $48 \mathrm{~h}$ : here, too, significant levels of cell death were induced (Fig. 4C). The results indicated that ammonium treatment induces SIRBOH-dependent cell death which can be reduced in the presence of ROS scavengers.

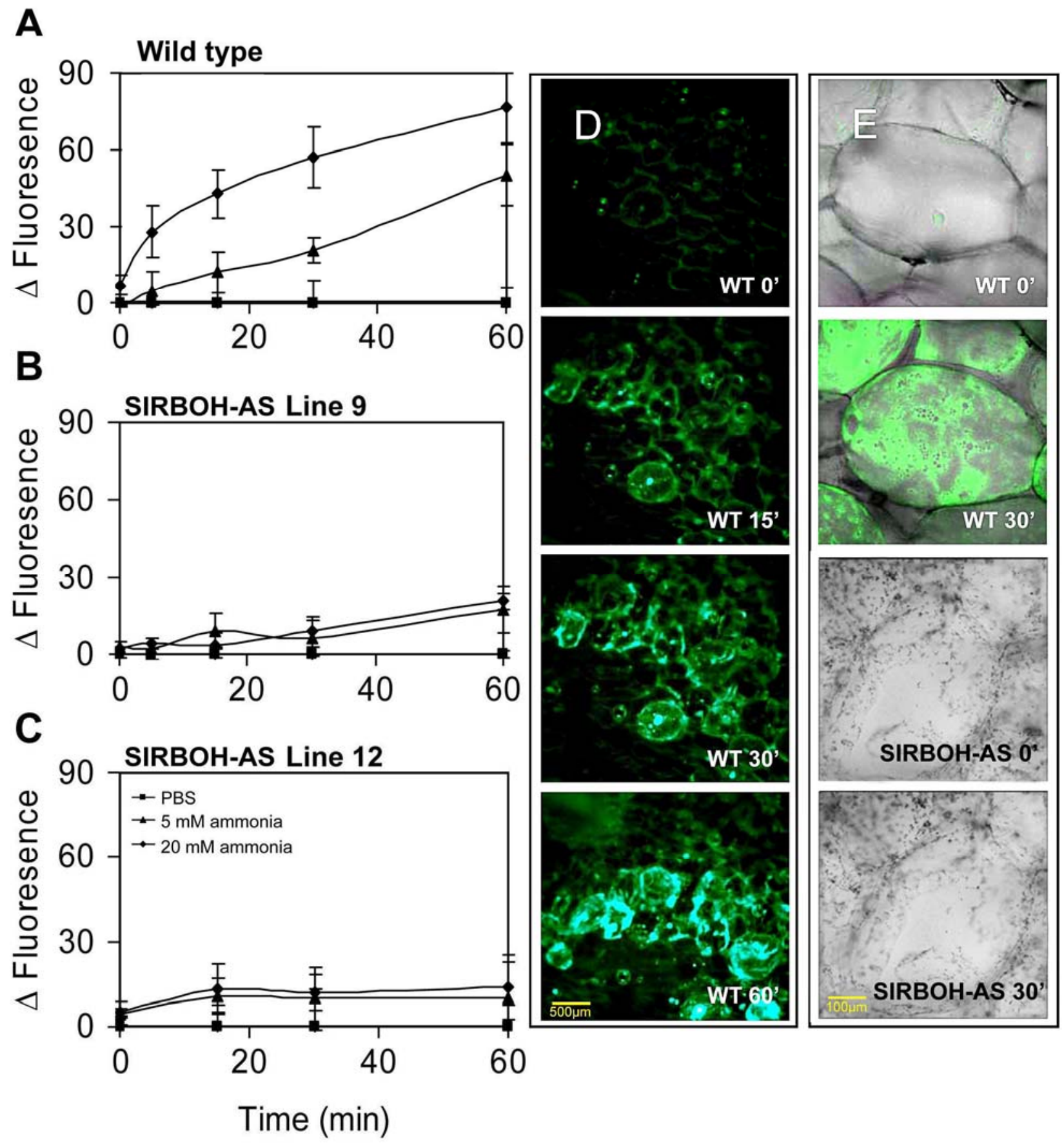

Fig. 2. Effect of ammonium on reactive oxygen species accumulation as measured by $2^{\prime}, 7^{\prime}$-dichlorodihydrofluorescein diacetate fluorescence in $\mathbf{A}$ and $\mathbf{D}$, wild-type (WT) and $\mathbf{B}$ and $\mathbf{C}$, SIRBOH-AS tomato fruit tissue. A, Fluorescence of WT tomato fruit tissue slices after application of: $5 \mathrm{mM} \mathrm{NH}_{4} \mathrm{Cl}$ in phosphate-buffered saline (PBS) $(\mathbf{\Lambda}), 20 \mathrm{mM} \mathrm{NH}_{4} \mathrm{Cl}$ in PBS $(\diamond)$, or PBS $(\mathbf{\square})$. All treatments were at $\mathrm{pH}$ 7.0. B and $\mathbf{C}$, Treatments and fluorescence measurements were carried out as in A with SIRBOH-AS line 9 and 12 tomato fruit tissue, respectively. D, Fluorescence binocular pictures were taken 0, 15, 30, and $60 \mathrm{~min}$ after $20 \mathrm{mM}$ ammonia application on WT tomato fruit tissue. E, Confocal microscope pictures were taken 0 and $30 \mathrm{~min}$ after $20 \mathrm{mM}$ ammonia application on tomato fruit tissue of the WT (upper two) and SIRBOH-AS (lower two). 
Contribution of the host response to $C$. coccodes infection.

To determine the effect of host ROS production and its contribution to the pathogenicity and necrotrophic development of C. coccodes on tomato, we inoculated wild-type and SIRBOHAS tomato fruit and followed its colonization pattern (Fig. 5). Both cultivars showed similar ammonium amounts and $\mathrm{pH}$ levels in the colonized tissue (Fig. 5A and B). However, the wild-type tomato fruit showed a significantly higher amount of ROS accumulation as detected by DCF fluorescence (Fig. 5C). Furthermore, wild-type tissue was more susceptible than the SIRBOH-AS strain to fungal colonization, as reflected by the larger decay diameter (Fig. 5D).

Activation of RBOH by ammonium is dependent upon pH.

Our previous data has shown that ammonium secretion is induced in $C$. coccodes at the ambient low $\mathrm{pH}$ present in fruit (Alkan et al. 2008). However, additional pathogenicity factors are activated when the host environment $\mathrm{pH}$ increases (Prusky et al. 2001). Therefore, it was of interest to study ammoniuminduced ROS production as a function of $\mathrm{pH}$. To this end, fruit tissue was exposed to PBS alone, or amended with $10 \mathrm{mM}$ $\mathrm{NH}_{4} \mathrm{Cl}$, at various pHs. Ammonium induction of $\mathrm{ROS}$ was strongly enhanced with an increase in $\mathrm{pH}$ from 4 to 8 (Fig. 6B). The observed increase in fluorescence was likely the result of DCF oxidation and not of changes in $\mathrm{pH}$, because DCF varies less than $30 \%$ over a $\mathrm{pH}$ range of 5.2 to 8 (Ge and Chen 2008). The increased ROS as a function of $\mathrm{pH}$ could be
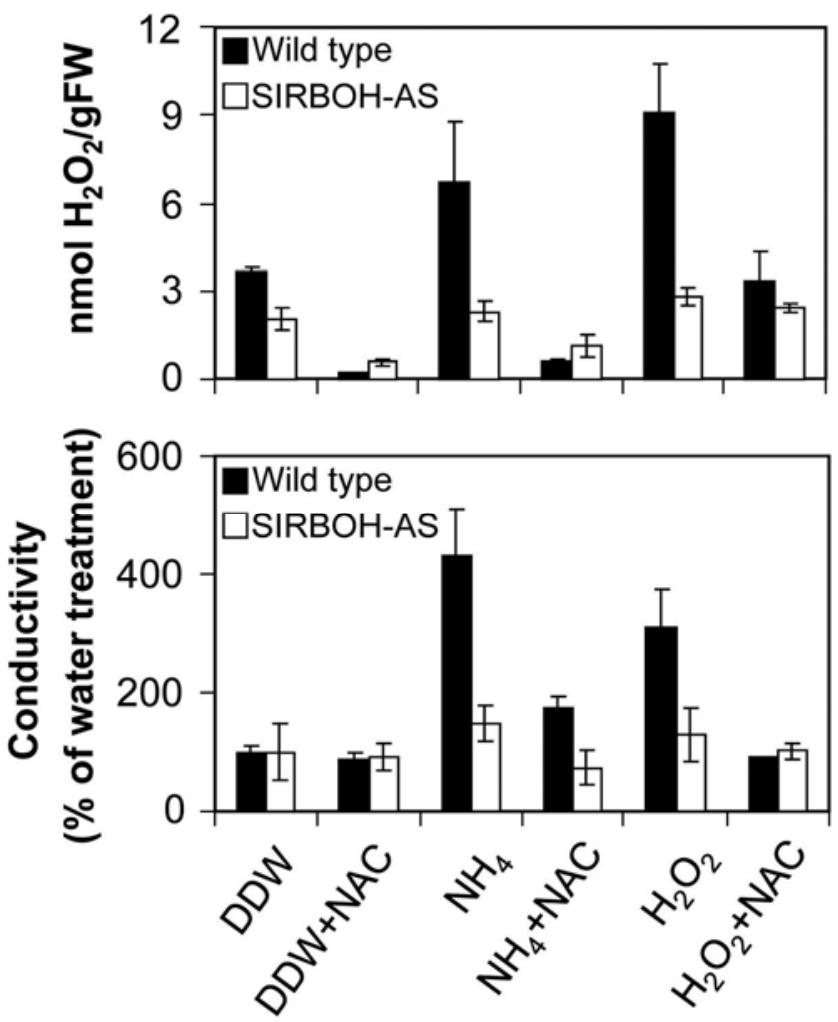

Fig. 3. $\mathrm{H}_{2} \mathrm{O}_{2}$ accumulation and electrolytic leakage in tomato fruit disks. Disks were pretreated with $\mathrm{H}_{2} \mathrm{O}_{2}, \mathrm{NH}_{4} \mathrm{Cl}$, or water, with or without $\mathrm{N}$-acetyl-L-cysteine (NAC). Treatment was for $30 \mathrm{~min}$ and then disks were washed and incubated for $2 \mathrm{~h}$. The experiments were carried out on wildtype (black column) and SIRBOH-AS (white column) tomato fruit disks. $\mathrm{H}_{2} \mathrm{O}_{2}$ was detected by Amplex red 15 min after pretreatment and incubation in phosphate-buffered saline (upper box). Electrolyte leakage was detected after $2 \mathrm{~h}$ by measuring conductivity (lower box). Numbers are expressed as percentage of the water treatment (double-distilled water) for each tomato line. Experiments are an average of four replicates, three disks per replicate. the result of differential penetration of the ammonium solution into the tomato parenchyma cells at each particular $\mathrm{pH}$. Indeed, it is expected that, at higher $\mathrm{pH}$, more neutral ammonium $\mathrm{NH}_{3}$ species will be present, and membrane permeability to the noncharged species is higher than that to the ionated $\mathrm{NH}_{4}{ }^{+}$species. The penetration of ammonium was estimated by measuring the degree of cytosol alkalization, using the fluorescent probe 2',7'-bis(carboxyethyl)-5(6)-carboxyfluorescein acetoxymethyl ester (BCECF, AM), in the presence of ammonium as a function of increasing $\mathrm{pH}$ from 4 to 7 . The cytosolic $\mathrm{pH}$ rose rapidly at $10 \mathrm{mM}$ ammonium at $\mathrm{pH} 7.0$ (Fig. 6A), the rise in cytosolic $\mathrm{pH}$ is likely the result of hydrogen ion uptake in the cytosol by the permeating $\mathrm{NH}_{3}$ form, which results in cytosol alkalization. These results suggested that internalization of ammonium and cytosolic $\mathrm{pH}$ changes both function in SIRBOH activation. Interestingly, when inorganic phosphate buffer was used at high concentrations $(50 \mathrm{mM}$; i.e., 5.7 -fold that found in PBS), a significant ROS response was also obtained concomitant with alkalization of the cytosol (Fig. 6C). Phosphate species likely penetrate via membrane phosphate transporters (Eckardt 2005; Gonzalez et al. 2005). In contrast, the nonpermeable phthalate buffer at $50 \mathrm{mM}$ and $\mathrm{pH} 7.0 \mathrm{did}$ not induce ROS or cause cytosolic alkalization (Fig. 6C).

\section{DISCUSSION}

Our observations established a direct correlation between ammonium accumulation and size of the $C$. coccodes infection court. Ammonium application by itself was found to directly activate ROS production in tomato tissue and the source of this ROS, as established by the use of SIRBOH antisense lines, was the tomato NADPH oxidase. Moreover, confocal observation (Fig. 2D) further established that the ROS activated by ammo-
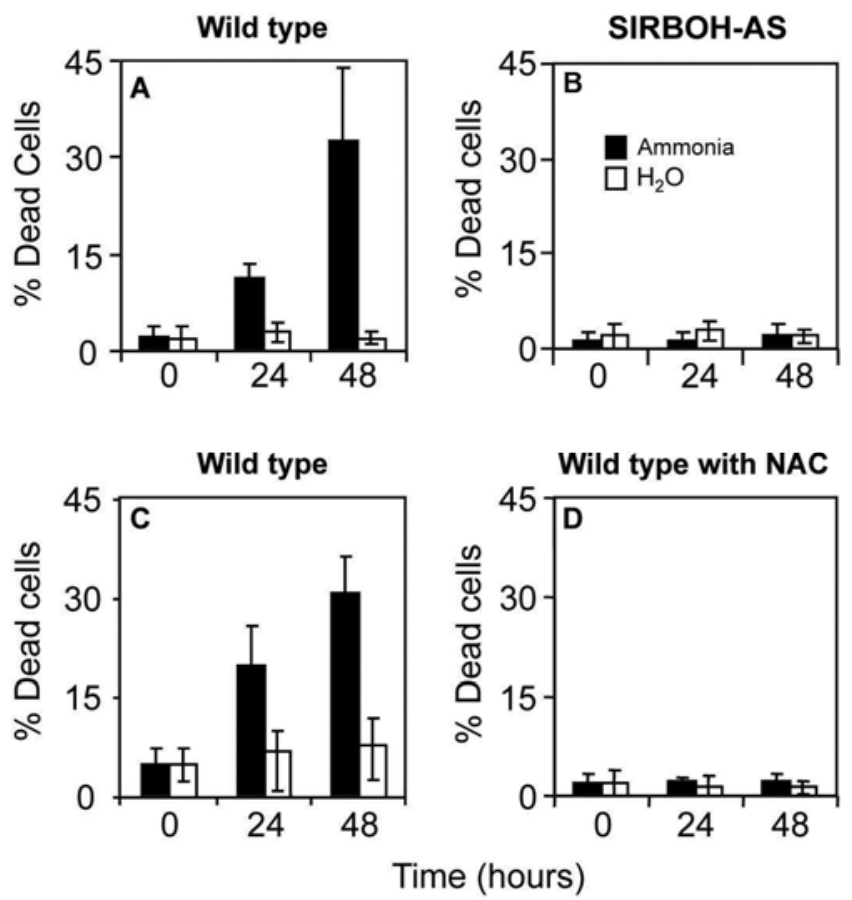

Fig. 4. Effect of ammonium on cell death in whole tomato fruit from wildtype and SIRBOH-AS lines. A, B, and D, Fruit was injected with water, ammonium, or simultaneously with $N$-acetyl-L-cysteine (NAC) and ammonium, respectively. Cell death at the injection site was detected 24 and $48 \mathrm{~h}$ after $50 \mathrm{mM} \mathrm{NH}{ }_{4} \mathrm{Cl}$ had been injected into the pericarp. Cell death was monitored by Evans blue staining. Treatments were $\mathbf{A}, \mathbf{C}$, and $\mathbf{D}$, wild type and $\mathbf{B}, \mathrm{SIRBOH}-\mathrm{AS}$. C, $5 \mathrm{mM} \mathrm{NH}_{4} \mathrm{Cl}$ was applied after removal of a 1-cm-diameter epidermal disk and reapplied every $4 \mathrm{~h}$. 
nium can be detected within the cell. Although $\mathrm{RBOH}$ protein has been detected on the plasmalemma (Keller et al. 1998; Sagi and Fluhr 2001; Kobayashi et al. 2006) and, in that case, would catalyze superoxide production outside of the cell, the DCF reporter can report only internal accumulation of $\mathrm{H}_{2} \mathrm{O}_{2}$ (Allan and Fluhr 1997; Ashtamker et al. 2007). Apparently, either the superoxide or its dismutated form $\left(\mathrm{H}_{2} \mathrm{O}_{2}\right)$ enters the cell.
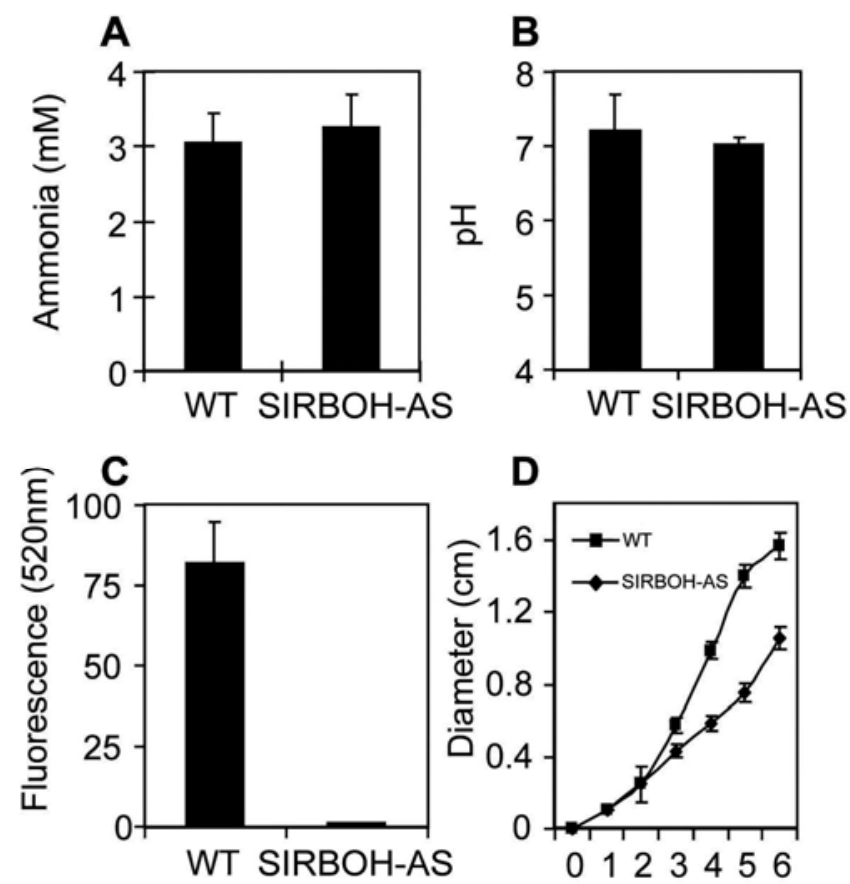

D

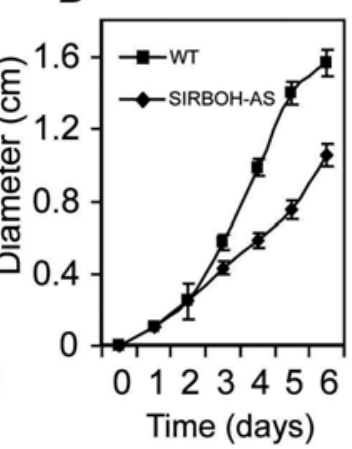

Fig. 5. Ammonium level, reactive oxygen species (ROS) accumulation, $\mathrm{pH}$ changes, and colonization diameter during Colletotrichum coccodes growth on wild-type (WT) and SIRBOH-AS tomato fruit. Spores of $C$. coccodes were injected into tomato mesocarp. $\mathbf{A}$ and $\mathbf{B}$, Ammonium and $\mathrm{pH}$, respectively, measured $48 \mathrm{~h}$ postinoculation. $\mathrm{C}$, ROS accumulation measured by $2^{\prime}, 7^{\prime}$-dichlorodihydrofluorescein diacetate fluorescence $48 \mathrm{~h}$ post-inoculation. D, Colonization diameter measured over the course of 6 days postinoculation. Micrographs of the treated area were analyzed by SigmaScan software.
Due to the lack of a full genomic sequence in tomato, the exact member of the SIRBOH multigene family that is involved is not known. However, a specific and direct reduction in total SIRBOH polypeptides (Wfil and SIRBOH1), total ROS, and wound-signal transduction was observed previously in SIRBOH-AS lines (Sagi et al. 2004). ROS accumulation was part of the signal for induced cell death, because this induction was abrogated by the addition of the ROS scavenger, NAC. Ammonium affected ion leakage of tomato cells (as determined by measuring conductivity) and cell death (as detected by Evans blue staining). The simplest scenario consistent with these observations is that ammonium secretion serves a dual purpose in $C$. coccodes colonization: as a signal for the synchronous induction of pathogenicity genes in the fungus and as an inducer of host ROS accumulation. In tomato fruit with reduced SIRBOH activity, these dual functions are separated: while the fungus continues to secrete ammonium and modify the infection court $\mathrm{pH}$, the mutant host tissue is less responsive in terms of ROS production and subsequent induction of cell death. Importantly, ammonium accumulation by the pathogen is independent of ROS accumulation and the fungus uses fruit $\mathrm{pH}$ as a cue for ammonium production (Prusky and Yakoby 2003).

Accumulation of ROS due to ammonium has been noted in other organisms. In human astrocytes, the application of ammonium was shown to activate NADPH oxidase (Reinehr et al. 2007). In yeast, an ammonium signal emitted by aging colonies triggered metabolic changes leading to yeast localized programmed cell death (Vachova and Palkova 2005). However, because yeast lack NADPH oxidases, the source of the ROS in that case must have been different (Kawahara et al. 2007).

Present observations, where ammonium activates NADPH oxidase and the accumulation of ROS, indicate a possible mechanism for understanding of the toxicity of ammonium to the host tissue (Medici et al. 2004). Presumably, as ammonium flows into the plant cell, increasing amounts of energy are diverted to its active removal. The resultant energy depletion is thought to be one agent of ammonium toxicity that can also have a negative effects on photosynthesis (Britto and Kronzucker 2006). Although energy depletion by ammonium may be a valid cause for toxicity at the whole-plant level during root solute interactions, it is unlikely to be the cause of cell death in tomato fruit; first, due to the rapidity of the reaction
A

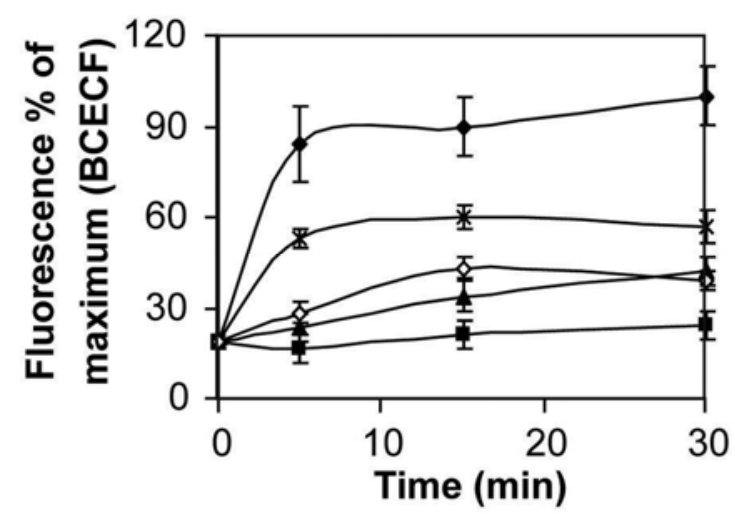

B

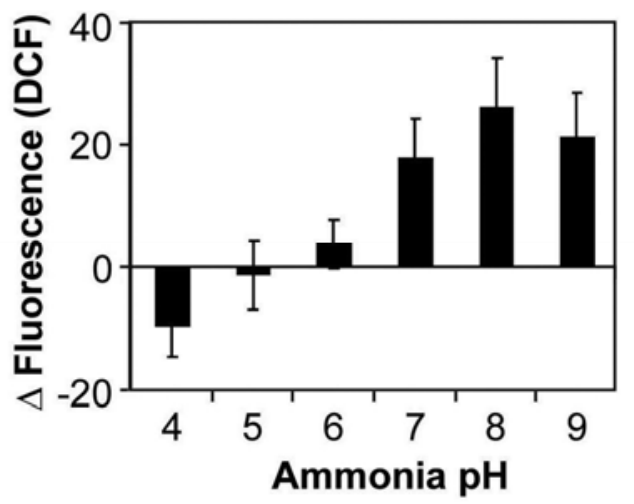

C

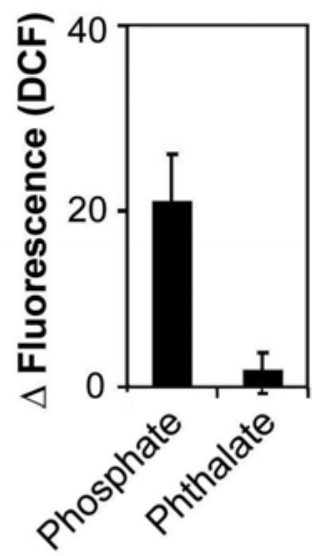

Fig. 6. Effect of ammonium applied at different pHs on reactive oxygen species (ROS) induction. A, Fluorescence measurements of $2^{\prime}, 7^{\prime}$-bis(carboxyethyl)5(6)-carboxyfluorescein acetoxymethyl ester (BCECF, AM) after application of: $10 \mathrm{mM} \mathrm{NH}_{4} \mathrm{Cl}$ at $\mathrm{pH} 4.0(\boldsymbol{\Delta})$ and $\mathrm{pH} 7.0(\bullet), 50 \mathrm{mM}$ phosphate at $\mathrm{pH} 7.0$ $(\times), 50 \mathrm{mM}$ phthalate at $\mathrm{pH} 7.0(\diamond)$, and $\mathrm{H}_{2} \mathrm{O}(\boldsymbol{\square})$. Results were recorded for $30 \mathrm{~min}$ after the treatments. B, 2',7'-Dichlorodihydrofluorescein diacetate (DCF) fluorescence measurements after application of $10 \mathrm{mM} \mathrm{NH}_{4} \mathrm{Cl}$ at different pHs. $\mathbf{C}$, DCF fluorescence measurements after application of $50 \mathrm{mM}$ phosphate and phthalate buffers at $\mathrm{pH}$ 7.0. The results are averages of 500 parenchyma cells. 
and, second, due to the fact that high concentrations of other ions, such as inorganic phosphate, also induce ROS in tomato tissue. Phosphate can penetrate plant cells and alkalize them in a manner similar to ammonium (Sakano 1990; Arif et al. 1995). We showed that ammonium alkalizes the cell cytosol more efficiently at higher $\mathrm{pH}$ and that the host cell reacts by accumulating more ROS. The ammonium ion import due to the extracellular excess can lead to perturbation of plasmalemma membrane charge homeostasis, which promotes $\mathrm{H}^{+}-$ ATPase activity to correct the changes in electronegativity (Pagliarani et al. 2008). Fluxes of this sort have been shown to precede $\mathrm{RBOH}$ activation.

Our data add to the increasingly complex picture of fruitpathogen interactions. The increasing availability of amino acids during fruit ripening (Boggio et al. 2000) may ensure ammonium production by the pathogen and contribute to initiating its shift from the biotrophic-quiescent stage to the necrotrophiccolonization stage (Prusky and Lichter 2007). The ability of the pathogen to accumulate large amounts of ammonium in decaying tissue contributes to increased $\mathrm{pH}$ and virulence (Alkan et al. 2008). In this work, we show that host ROS production is a target for the accumulated ammonium. Our results suggest that ammonium secretion is a key factor modulating host physiology near the hyphae's leading edge by subverting host cellular signals to the benefit of Colletotrichum spp. necrotrophic growth. A similar conclusion was recently suggested by Asai and Yoshioka (2009), who reported the possible involvement of RBOH in host cell death resulting in the enhanced necrotrophic development of $B$. cinerea. Therefore, altering ammonium secretion, $\mathrm{pH}$-regulated processes, or ROS scavenging could form the basis for a viable strategy to delay, reduce, or even prevent disease development by this plant-pathogenic fungus.

\section{MATERIALS AND METHODS}

\section{Plant material, fungal strains, media, and growth conditions.}

$S$. lycopersicum cv. Motelle wild-type and transgenic plants expressing SlRBOH (AAD25300) and Wfil (AF73124) fragments in sense and antisense orientation, respectively, were used to obtain SIRBOH-AS line 9 and line 12. They are independent isolates of the M3-type lines as described by Sagi and associates (2004). The plants were grown in pots filled with a peat-vermiculite $(4: 1, \mathrm{vol} / \mathrm{vol})$ mixture containing slow-release high-N Multicote 4 with microelements $(0.3 \%$ wt/wt; Haifa Chemicals, Haifa Bay, Israel). Average temperatures in the greenhouse during the growth period fluctuated from 18 to $25^{\circ} \mathrm{C}$. All experiments were preformed on $S$. lycopersicum cv. Motelle wild-type and transgenic plants SIRBOH-AS line 9 and line 12.

C. coccodes isolate 138 , pathogenic on tomato fruit, was obtained from decayed potato tubers in Israel (supplied by L. Tzror, Agricultural Research Organization) (Nitzan et al. 2002). Single-spore cultures were maintained routinely on Mathur's medium (M3S) (Tu 1985) containing chloramphenicol at $250 \mathrm{mg} / \mathrm{liter}$. Spores of the original single-spore culture were maintained in $40 \%$ glycerol at $-80^{\circ} \mathrm{C}$ as a source of inoculum. C. coccodes nit $1^{-}$and nit $3^{-}$mutants were generated in the presence of potassium chlorate (Alkan et al. 2008). C. coccodes are $A^{-}$(strains 752, 787, 757, and ectopic 801) mutant lines were obtained by direct hygromycin insertion using the Gateway system (Alkan et al. 2008).

\section{Fruit inoculation, fruit treatments, and infection parameters.}

For inoculation with fungal hyphae, freshly harvested mature color-break tomato fruit of the same age and size ( $S$. lycopersicum cv. Hazera 1402, susceptible to C. coccodes) were used for inoculations. Fruit inoculation was carried out on the mesocarp. A 1-mm-thick, 10-mm-diameter piece of the peel pericarp tissue was removed from the fruit and replaced by a 1-mm-thick hyphal disk of $C$. coccodes mycelia showing different levels of reduction of ammonium secretion as wild type, nit1 $^{-}$(nitrate reductase), nit $3^{-}$(nitrite reductase), and are $\mathrm{A}^{-}$ mutants (major nitrogen regulation factor) (Alkan et al. 2008). This hyphal disk was obtained after growing spores for 3 days on primary media and 1 day on secondary media (Alkan et al. 2008). Following inoculation, fruit were incubated at $22^{\circ} \mathrm{C}$ and $95 \%$ relative humidity in plastic containers. In some experiments, the inoculation sites were exogenously treated by pipetting $50 \mu \mathrm{l}$ of phthalate at different pHs, or $10 \mathrm{mN} \mathrm{KNO}_{3}$, glutamine, or ammonia. The diameter of decay development was measured $48 \mathrm{~h}$ after inoculation and reported in centimeters over the 1-cm diameter of infection with the hyphae mat. The ammonium concentration in the decayed tissue was measured $48 \mathrm{~h}$ after inoculation (as described below).

\section{Fluorescence and staining methods.}

Changes in tissue ROS and $\mathrm{pH}$ were detected using the fluorescent probes DCF D-399 and BCECF, AM B-1150, respectively (Molecular Probes, Invitrogen, Leiden, The Netherlands). Staining for ROS and $\mathrm{pH}$ evaluation in infected and noninfected tomato tissue were performed by exposing the tissue to $10 \mu \mathrm{M}$ DCF or BCECF, AM, respectively, for $15 \mathrm{~min}$ in the dark at $24^{\circ} \mathrm{C}$ and then rinsing the sample twice in PBS. Sampling of the tissue for ROS and $\mathrm{pH}$ evaluation was performed by slicing $1-\mathrm{mm}$-thick by $20-\mathrm{mm}$-long parenchyma fruit strips from the tomato pericarp and mesocarp tissue diagonal to the surface area. The strips were viewed with a Leica fluorescence binocular or a laser-scanning confocal microscope (Olympus IX81). Intracellular fluorescence was excited at $488 \mathrm{~nm}$ and emission was detected at $520 \mathrm{~nm}$. The picture was then analyzed by SigmaScan software (SYSTAT) to obtain the average green fluorescence for each strip for both $\mathrm{pH}$ and ROS measurements.

To examine the effect of ammonium on ROS accumulation, parenchyma strips from the wild type and SIRBOH-AS lines 9 and 12 were stained with DCF and rinsed in 5 or $20 \mathrm{mM}$ $\mathrm{NH}_{4} \mathrm{Cl}$, or $\mathrm{H}_{2} \mathrm{O}$ as a control (all solutions were at $\mathrm{pH}$ 7.0). The strips were viewed with a Leica fluorescence binocular and with a laser-scanning confocal microscope (Olympus IX81). To examine ROS induction and $\mathrm{pH}$ change following ammonium application at different $\mathrm{pHs}$, the parenchyma strips were stained with DCF or BCECF, AM, respectively, and rinsed with $10 \mathrm{mM} \mathrm{NH}_{4} \mathrm{Cl}$ at $\mathrm{pH} 4.0$ to 9.0 , or with $50 \mathrm{mM}$ phthalate or phosphate buffered to $\mathrm{pH}$ 7.0. For DCF staining, pictures were taken after $60 \mathrm{~min}$ and, for BCECF, AM staining after 30 min, and then analyzed with SigmaScan software.

During the conductivity experiments, $\mathrm{H}_{2} \mathrm{O}_{2}$ concentration was determined $15 \mathrm{~min}$ after pretreatment with double-distilled water, ammonium, and $\mathrm{H}_{2} \mathrm{O}_{2}$ (described below). The level of $\mathrm{H}_{2} \mathrm{O}_{2}$ secreted from tomato fruit disks was measured by mixing $50 \mu \mathrm{l}$ of the surrounding liquid with $50 \mu \mathrm{l}$ of Amplex red $(100 \mu \mathrm{M})$ in the presence of horseradish peroxidase at $0.2 \mathrm{U} / \mathrm{ml}$ (Invitrogen, Molecular Probes). The samples were measured using the Microplate Fluorescence Reader FL600 (BioTek Instruments, Winooski, VT, U.S.A.) by excitation at $530 \mathrm{~nm}$ and emission at $590 \mathrm{~nm}$. Measurements were taken for 30 min every 3 min.

For cell-viability measurements, wild-type or SIRBOH-AS tomato fruit were injected with $50 \mu \mathrm{l}$ of 0 or $50 \mathrm{mM} \mathrm{NH}_{4} \mathrm{Cl}$ with or without $10 \mathrm{mM}$ NAC (ROS scavenger). Alternatively, $50 \mu \mathrm{l}$ of $5 \mathrm{mM} \mathrm{NH}_{4} \mathrm{Cl}$ was applied every $6 \mathrm{~h}$ to the fruit mesocarp after a 1-mm-thick, 10-mm-diameter piece of pericarp tissue was removed from the fruit. At 24 or $48 \mathrm{~h}$ after treatment, 
1-mm-thick strips were taken from the ammonia application site, diagonal to the surface. These strips were stained with $0.2 \%$ (wt/vol) Evans blue at room temperature for $5 \mathrm{~min}$ and destained by rinsing the strips several times in PBS. The strips were viewed with a Leica fluorescence binocular and the percentage of dead cells was calculated.

All experiments were repeated at least two times, with the results of a single representative experiment shown.

\section{Conductivity measurements.}

Wild-type or SIRBOH-AS tomato fruit pericarp disks $(10 \mathrm{~mm}$ in diameter) were tested. The disks were cut to a $10-\mathrm{mm}$ depth using a scalpel. Half of the disks were pretreated with $10 \mathrm{mM}$ NAC (ROS scavenger) for $30 \mathrm{~min}$ and the other half were treated with PBS. Subsequently, all disks were treated with $5 \mathrm{ml}$ of $20 \mathrm{mM} \mathrm{NH}_{4} \mathrm{Cl}, 1 \mathrm{mM} \mathrm{H}_{2} \mathrm{O}_{2}$, or PBS for 30 min with shaking at $50 \mathrm{rpm}$. For ROS measurements, three treated disks were placed in a 35-mm-diameter well containing $5 \mathrm{ml}$ of PBS and, after $15 \mathrm{~min}$, the surrounding liquid was checked for secreted $\mathrm{H}_{2} \mathrm{O}_{2}$ by Amplex red (as described above). The surrounding liquid was monitored for up to $2 \mathrm{~h}$ for conductivity by the autoranging conductivity meter TH-2300 (El-Hamma, Israel) with a Russell Thermo Electron Corp. (Russell/ThermoElectron, Auchtemuchty, Scotland) with a platinum conductivity electrode. Each treatment had four replicates. Experiments were repeated twice, with the results of a single representative experiment shown.

\section{Fruit inoculation with $C$. coccodes.}

Fruit inoculation was carried out by direct wound inoculation into the mesocarp and by the hyphal mat infection method described before (Alkan et al. 2008). The direct wound inoculation was carried out by injecting 5,000 spores of $C$. coccodes at a 2-mm depth onto the mesocarp of mature breaker-stage tomato fruit that had been surface sterilized in $0.3 \%$ ( $\mathrm{vol} / \mathrm{vol}$ ) hypochlorite for $10 \mathrm{~min}$ and then rinsed thoroughly with water. For each experiment, 10 tomato fruit were inoculated. Fruit were inoculated on both sides and placed in $100 \%$ relative humidity in the dark at $25^{\circ} \mathrm{C}$. Disease evaluation of inoculated tomato fruit included measurements of: i) decay diameter (in centimeters) for 6 days postinoculation; ii) ammonium, by ammonium test kit (Merck, Darmstadt, Germany); iii) pH, by Hamilton surface electrode; and iv) confocal microscope analysis after DCF staining (as described above) together with SigmaScan software (as described above). Ammonium, $\mathrm{pH}$, and microscope measurements were taken $48 \mathrm{~h}$ postinoculation. Experiments were repeated three times, with the results of a single representative experiment shown.

\section{Detection of ammonium and $\mathrm{pH}$ at the infection site.}

Infected fruit tissue $(1.5 \mathrm{~g})$ was homogenized and then centrifuged at $10,000 \mathrm{rpm}$ for $5 \mathrm{~min} ; 50 \mu \mathrm{l}$ of the supernatant was diluted to $5 \mathrm{ml}$ and ammonium was measured using the photometric ammonium test kit (Ammonium Test; Merck) to determine the final concentration in the supernatant.

The $\mathrm{pH}$ at the center of the infection site was measured with a stinging-type electrode (Eutech, Singapore). Pericarp pH was determined by making an approximately 0.2 -mm-deep cut with a scalpel. The $\mathrm{pH}$ measurements were made by placing the electrode directly against the exposed tissue. The depth of the pericarp cut was determined based on the localization of the infection.

\section{Statistical analyses.}

Linear regression and Pearson correlation were performed using SPSS statistical software to determine the $P$ value of the regression, and the $R^{2}$ and significance of the correlation.

\section{ACKNOWLEDGMENTS}

This work was supported by the United States-Israel Binational Agricultural Research and Development Fund (research grant number IS-394506). We thank B. Eduard for his help with the confocal microscope.

\section{LITERATURE CITED}

Alkan, N., Fluhr, R., Sherman, A., and Prusky, D. 2008. Role of ammonia secretion and $\mathrm{pH}$ modulation on pathogenicity of Colletotrichum coccodes on tomato fruit. Mol. Plant-Microbe Interact. 21:1058-1066.

Allan, A., and Fluhr, R. 1997. Two distinct sources of elicited reactive oxygen species in tobacco epidermal cells. Plant Cell 9:1559-1572.

Arif, I., Newman, I., and Keenlyside, N. 1995. Proton flux measurements from tissues in buffered solution. Plant Cell Environ. 18:1319-1324.

Asai, S., and Yoshioka, H. 2009. Nitric oxide as a partner of reactive oxygen species participates in disease resistance to necrotrophic pathogen Botrytis cinerea in Nicotiana benthamiana. Mol. Plant-Microbe Interact. 22:619-629.

Ashtamker, C., Kiss, V., Sagi, M., Davydov, O., and Fluhr, R. 2007. Diverse subcellular locations of cryptogein-induced reactive oxygen species production in tobacco bright yellow-2 cells. Plant Physiol. 143:1817-1826.

Boggio, S., Palatnik, J., Heldt, H., and Valle, E. 2000. Changes in amino acid composition and nitrogen metabolizing enzymes in ripening fruits of Lycopersicon esculentum Mill. Plant Sci. 159:125-133.

Britto, D., and Kronzucker, H. 2006. Futile cycling at the plasma membrane: A hallmark of low-affinity nutrient transport. Trends Plant Sci. 11:529-534.

Britto, D. T., and Kronzucker, H. J. 2002. $\mathrm{NH}_{4}{ }^{+}$toxicity in higher plants: A critical review. J. Plant Physiol. 159:567-584.

D'Autreaux, B., and Toledano, M. B. 2007. ROS as signalling molecules: Mechanisms that generate specificity in ROS homeostasis. Nat. Rev. Mol. Cell Biol. 8:813-824.

Delledonne, M., Xia, Y., Dixon, R., and Lamb, C. 1998. Nitric oxide functions as a signal in plant disease resistance. Nat. Rev. Mol. Cell Biol. 394:585-588.

Eckardt, N. 2005. Insights into plant cellular mechanisms: Of phosphate transporters and arbuscular mycorrhizal infection. Plant Cell 17:32133216.

Ge, F., and Chen, L. 2008. pH fluorescent probes: Chlorinated fluoresceins. J. Fluorescence 18:741-747.

Gilchrist, D. G. 1998. Programmed cell death in plant disease: The purpose and promise of cellular suicide. Annu. Rev. Phytopathol. 36:393414.

Glazebrook, J. 2005. Contrasting mechanisms of defense against biotrophic and necrotrophic pathogens. Annu. Rev. Phytopathol. 43:205-227.

Gonzalez, E., Solano, R., Rubio, V., Leyva, A., and Paz-Ares, J. 2005. Phosphate transporter traffic facilitator1 is a plant-specific SEC12related protein that enables the endoplasmic reticulum exit of a highaffinity phosphate transporter in Arabidopsis. Plant Cell 17:3500-3512.

Govrin, E., and Levine, A. 2000. The hypersensitive response facilitates plant infection by the necrotrophic pathogen Botrytis cinerea. Curr. Biol. 10:751-757.

Greenberg, J. T. 1997. Programmed cell death in plant-pathogen interactions. Annu. Rev. Plant Physiol. Plant Mol. Biol. 48:525-545.

Kawahara, T., Quinn, M., and Lambeth, J. 2007. Molecular evolution of the reactive oxygen-generating NADPH oxidase (Nox/Duox) family of enzymes. BMC Evol. Biol. 7:109.

Keller, T., Damude, H., Werner, D., Doerner, P., Dixon, R., and Lamb, C. 1998. A plant homolog of the neutrophil NADPH oxidase gp91(phox) subunit gene encodes a plasma membrane protein with $\mathrm{Ca} 2+$ binding motifs. Plant Cell 10:255-266.

Kliebenstein, D., and Rowe, H. 2008. Ecological costs of biotrophic versus necrotrophic pathogen resistance, the hypersensitive response and signal transduction. Plant Sci. 174:551-556.

Kobayashi, M., Kawakita, K., Maeshima, M., Doke, N., and Yoshioka, H. 2006. Subcellular localization of Strboh proteins and NADPH-dependen $\mathrm{O}_{2}{ }^{-}$-generating activity in potato tuber tissues. J. Exp. Bot. 57:1373-1379.

Kuzniak, E., and Sklodowska, M. 2005. Fungal pathogen-induced changes in the antioxidant systems of leaf peroxisomes from infected tomato plants. Planta 222:192-200

Latunde-Dada, A. O. 2001. Colletotrichum: Tales of forcible entry, stealth, transient confinement and breakout. Mol. Plant Pathol. 2:187-198.

Mathieu, Y., Jouanneau, J. P., Thomine, S., Lapous, D., and Guern, J. 1994. Cytosolic protons as secondary messengers in elicitor-induced defense responses. Pages 113-130 in: Molecular Botany: Signals and the Environment. D. J. Bowles, P. M. Gilmartin, J.P. Knox, and G.G. Lunt, eds. Biochemistry Society Symposium. Portland Press, London. 
Medici, L., Azevedo, R., Smith, R., and Lea, P. 2004. The influence of nitrogen supply on antioxidant enzymes in plant roots. Funct. Plant Biol. 31:1-9.

Nitzan, N., Hazanovsky, M., Tal, M., and Tsror, L. 2002. Vegetative compatibility groups in Colletotrichum coccodes, the causal agent of black dot on potato. Phytopathology 92:827-832.

Pagliarani, A., Bandiera, P., Ventrella, V., Trombetti, F., Manuzzi, M., Pirini, M., and Borgatti, A. 2008. Response of $\mathrm{Na}^{+}$-dependent ATPase activities to the contaminant ammonia nitrogen in Tapes philippinarum: Possible ATPase involvement in ammonium transport. Arch. Environ. Contam. Toxicol. 55:49-56.

Prusky, D. 1996. Pathogen quiescence in postharvest diseases. Annu. Rev. Phytopathol. 34:413-434.

Prusky, D., and Lichter, A. 2007. Activation of quiescent infections by postharvest pathogens during transition from the biotrophic to the necrotrophic stage. FEMS (Fed. Eur. Microbiol. Soc.) Microbiol. Lett. 268:1-8.

Prusky, D., and Yakoby, N. 2003. Pathogenic fungi: Leading or led by ambient pH? Mol. Plant Pathol. 4:509-516.

Prusky, D., McEvoy, J. L., Leverentz, B., and Conway, W. S. 2001. Local modulation of host $\mathrm{pH}$ by Colletotrichum species as a mechanism to increase virulence. Mol. Plant-Microbe Interact. 14:1105-1113.

Reinehr, R., Gorg, B., Becker, S., Qvartskhava, N., Bidmon, H. J., Selbach, O., Haas, H. L., Schliess, F., and Haussinger, D. 2007. Hypoosmotic swelling and ammonia increase oxidative stress by NADPH oxidase in cultured astrocytes and vital brain slices. Glia 55:758-771.

Sagi, M., and Fluhr, R. 2001. Superoxide production by plant homologues of the gp91 ${ }^{\text {phox }}$ NADPH oxidase. Modulation of activity by calcium and by tobacco mosaic virus infection. Plant Physiol. 126:1281-1290.

Sagi, M., and Fluhr, R. 2006. Production of reactive oxygen species by plant NADPH oxidases. Plant Physiol. 141:336-340.

Sagi, M., Davydov, O., Orazova, S., Yesbergenova, Z., Ophir, R., Stratmann, J. W., and Fluhr, R. 2004. Plant respiratory burst oxidase homologs impinge on wound responsiveness and development in Lycopersicon esculentum. Plant Cell 16:616-628.

Sakano, K. 1990. Proton phosphate stoichiometry in uptake of inorganicphosphate by cultured cells of Catharanthus roseus (L.) G. Don. Plant Physiol. 93:479-483.

Shetty, N., Jorgensen, H., Jensen, J., Collinge, D., and Shetty, H. 2008. Roles of reactive oxygen species in interactions between plants and pathogens. Eur. J. Plant Pathol. 121:267-280.

Torres, M. A., Dangl, J. L., and Jones, J. D. G. 2002. Arabidopsis gp91 ${ }^{\text {phox }}$ homologues AtrbohD and AtrbohF are required for accumulation of reactive oxygen intermediates in the plant defense response. Proc. Nat. Acad. Sci. U.S.A. 99:517-522.

Tu, J. C. 1985. An improved Mathur's medium for growth, sporulation, and germination of spores of Colletotrichum lindemuthianum. Microbios 44:87-93.

Vachova, L., and Palkova, Z. 2005. Physiological regulation of yeast cell death in multicellular colonies is triggered by ammonia. J. Cell Biol. 169:711-717.

Yakoby, N., Kobiler, I., Dinoor, A., and Prusky, D. 2000. pH regulation of pectate lyase secretion modulates the attack of Colletotrichum gloeosporioides on avocado fruits. Appl. Environ. Microbiol. 66:1026-1030. 